\title{
The Influence of the Forms of Exercise and Leg Muscle Power towards Breast Stroke Skills
}

\author{
Saharuddin $\mathrm{Ita}^{1}$ \\ ${ }^{1}$ Universitas Cenderawasih, Jayapura, Indonesia \\ Correspondence: Saharuddin Ita, Universitas Cenderawasih, Kampus UNCEN Waena, Jl. Camp Wolker, \\ Jayapura, Indonesia. E-mail: saharuddinita@yahoo.com
}

Received: January 16, 2014

Accepted: February 20, 2014 Online Published: February 28, 2014

doi:10.5539/ass.v10n5p104

URL: http://dx.doi.org/10.5539/ass.v10n5p104

\begin{abstract}
The purposes of this research are: 1) to know the differences bucket kick exercise and tube kick exercise on breast stroke skill, 2) to know the differences between bucket kick exercise and tube kick exercise for the students having high leg muscle power on breast stroke skill, 3) to know the differences between bucket kick exercise and tube kick exercise for the students having low leg muscle power on breast stroke skill, and 4) to know the interaction between types of exercise and the leg muscle power on breast stroke skills. The sample for this research is 44 students. The method of research is experimental with $2 \mathrm{X} 2$ factorial design. The data was analyzed using ANOVA and Tukey test and the level of significance is set at 0.05. Results showed that there is a difference between bucket kick and tube kick exercises on breast stroke skill, bucket kick exercise is better than tube kick for the students having high leg muscle power on breast stroke skill, tube kick exercise is better than bucket kick exercise for the students having low leg muscle power on breast stroke skill, and, there is an interaction between the type of exercise and the leg muscle power towards breast stroke skill.
\end{abstract}

Keywords: type of exercise, bucket kick, tube kick, breast stroke skill

\section{Introduction}

Early observation of the breaststroke swimming style was focused on the formation of a good basic swimming skill based on the mechanics of swimming styles. A breaststroke swimmer must have the style of his own as well as the existing mechanics in breaststroke swimming. Thus, the type of training should pay attention to the principle of specific characteristics, especially certain physical conditions that could support the skills of an athlete to achieve maximum performance. In order to apply breaststroke, an individual must possess good mastery of basic swimming techniques such as; body position in the water, arm movements, leg movements, breathing and the coordination of movements and adding to it is the starting and finishing.

Maglischo (1993) said that leg plays a more dominant role than the arm movement in breaststroke training. Maglischo states that 60 percent of breaststroke movement is leg movement. It means that $60 \%$ of the power is produced by the legs, and $40 \%$ by the arm. Maglischo further said that in a few thousand meters of total training given to breaststroke swimmers, $75-80 \%$ of training program materials focus on the legs, either on endurance or on speed (Maglischo, 1993). Counsilman, swimming head coach at UCLA United States said that to increase the explosive power and muscles endurance, swimmers should use weight training, because by doing weight training, breaststroke swimmer will get power especially from the leg section (Counsilman, 1977). Furthermore, Luttgens and Hamilton (1997) stated that to get a big boost on strength and good breaststroke technique, then leg muscles force must be strengthen by doing weight training.

Bompa (1994) state that the first and main thing that should be fixed up in the training of sports achievement is the physical factor. If an athlete has good physical condition, other factors such as technique, tactics and strategies will follow. Otherwise, when an athlete's physical condition is not good, then the others will go through the same thing. Therefore, the importance of physical exercise training program should not be overlooked (Bompa, 1994). Bompa further said that physical exercise can be made through a model or form. The creation of a form of exercise based on a thought then analysing it, should be implemented later on the field (action), because a model or form of exercise is closely linked to the development of psychomotor skills (Bompa, 1994). 
The term 'skill' is used to describe or give a value on skills and strengths as well as the ability of a person at a certain level. According to Singer (1980), skill is a level or degree of success of the ability to achieve effectiveness and efficiency which is determined by speed and accuracy. Furthermore, Gagne (1992) said that psychomotor skill is integrated responses that is often combined in more complex activities through behavior changes as a result of learning in the psychomotor domain. Dalmonte (1976) said that skill is the ability to perform fast and precise movements harmoniously in one series.

Singer (1978) states that skill is a psychomotor ability of someone to perform a movement. Skill is a general quality a person possesses that facilitate his/her movements in performing specific skill in a sport. In breaststroke swimming, the skill an athlete must refers to is the physical ability to perform the movement with specific mechanics which begins with the start, glide, leg movements, arm movements, breathing, movement coordination and finishing. Mastery of a skill is a process of the responses received and then developed into a movement pattern planned and organized, so that the higher a person's success in achieving the goals set, the higher is the skill of the person (Sage, 1984).

Breaststroke is as a very technical style of swimming that requires very high coordination of movement skills. In order to achieve movement coordination in breaststroke swimming, several factors need to be considered, such as, intelligence of the athletes, accuracy and speed, experience of motion, and the development of other psychomotor abilities. Experience of motion will come from how much movement do the athletes do in practice and how long one exercises that can be completed by the athlete in a training session (Guyton, 1994). Good coordination between the movement of the arms, legs and breathing is also necessary for breast stroke swimmers.

When someone starts to move by using the muscles as a source of motion, the nervous system will automatically adjust for muscle contractions. For proper functioning of a movement, not only muscle excitation by anterior motoric neurons is required, but continuous transmission of feedback from each muscle to the nervous system is necessary (Guyton, 1994).

Breaststroke is a swimming style whereby the abdomen and body position remained unchanged from the beginning until the end. The pulling and pushing motion of both arms and legs should always be the same in the horizontal plane, taking a breath after each cycle of arm pull-leg push action. Swimmer's head must break the surface of the water (FINA Rules, 2005-2009) in every breaststroke swimming cycle. The basic breaststroke swimming techniques by Haller (1996) are: Body position, arm movements, leg movements, breathing and coordination. Furthermore, it is said that the series in a whole breaststroke swimming went through some phases namely; leg kick phase, glide phase, pull arm phase, elbow bent phase and recovery phase (Haller, 1996).

Breaststroke is a swimming style that is very specific when viewed from leg movements and arm movements, either at increasing the speed of swimmers or maintaining the body position to remain as flat as possible with water or streamline. According to Bunn (1972), the movement of breaststroke swimming is the only movement that is very quiet. Additionally, Hogg (1982) said that the leg is a major source of pulling in the breaststroke so that the rate of strength or pulling on the breaststroke is dominantly generated by leg pulling. Richard (2005) said that the breaststroke is a quiet swimming style, because the pulling power to move ahead in the glide is the result of a series of movements between the legs and arms with proper coordination and timing. Therefore, Richard further continued that the dominant push power of breaststroke is generated by the dominance of leg movement. However, the result of the breaststroke has relatively large resistance. This is caused by the position of the arm and leg while pulling and pushing are always below the water surface so that the swimming speed of breaststroke is slower when compared to other styles of swimming because of big resistance when the swimmer accelerates. However, according to Sweetenham (2003), breaststroke is slightly more efficient in energy use when compared to other swimming style because legs movement during acceleration is in the form of step and not kick like the other swimming styles' leg movements. As a result of the steps formed, the action of the breaststroke's leg movement practically is little more focused and refined when compared to the leg movements of other swimming styles' such as freestyle, backstroke and butterfly styles. Based on the above theory, it can be concluded that breaststroke swimming skills in this research is the ability to perform breaststroke swimming with basic techniques as well as coordinated with smooth, precise and fast movements.

Forms of exercise is closely linked to the development of psychomotor skills. A form of a model is a shadow of what is actually significantly acquired through abstract thinking. The purpose of the form itself is for the swimmer to practice the ideal movement. (Ernest, 2004).

Two forms of exercise for leg power is introduced. Kick the bucket training provide the swimmer with loads by using special straps tied around the waist at one end and using parachute at the other end to form loads. Hands 
are supported by a float board and swimmers will swim using breaststroke action of the legs (see Figure 1).

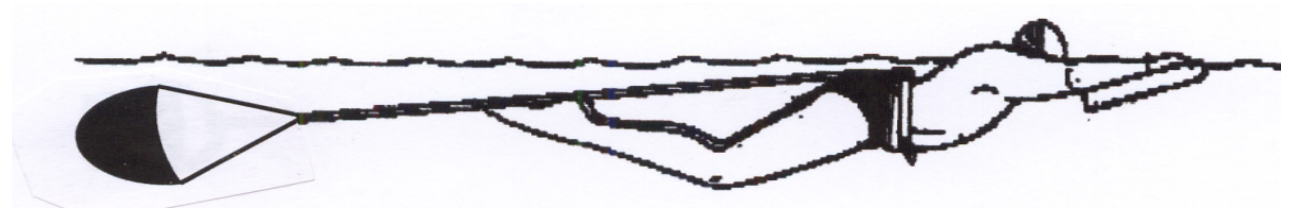

Figure 1. Kick the bucket training forms

Source: Ernest W. Maglischo. Swimming Even Faster (USA: Human Kinetics, Champign, 1993), p. 102

The other form of training is the tube kick. In this form, a band is anchored to the wall of the pool and the other end of the band is tied to the swimmers waist. Both arms is supported by the float board and the swimmer uses the correct breaststroke leg movement to swim (see Figure 2).

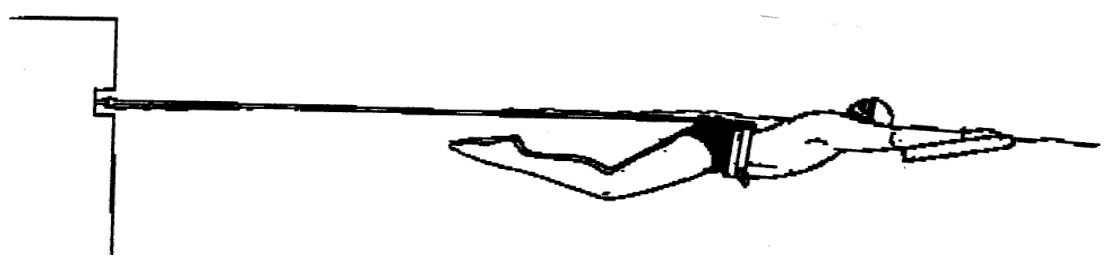

Figure 2. Tube kick training form

Source: Ernest W. Maglischo. Swimming Even Faster (USA: Human Kinetics, Champign, 1993), p. 22

Strength according to Pate and Rotella (1993) is the ability to deploy maximum force. According to Sharkey (1986), power is an attempt to use the maximum power of a person, while, according Licholat (1989), it is the ability of a group of muscle to overcome the maximum resistance. Based on the above definitions, it can be summarized that the leg muscle strength is the ability of a group of leg muscles to withstand the maximum load.

\section{Research Methodology}

This is an experimental research using a $2 X 2$ factorial design (Sujana, 1994), with a sample of 80 students randomly chosen from the population of students taking a coaching course. The samples were randomly divided into 2 groups, 40 students in the kick the bucket group (A1) and 40 students in the tube kick group (A2). Leg muscle strength of all samples were then taken to determine the attributes of high leg muscle strength and low leg muscle strength using the percentage technique introduced by Verducci (1980). The percentage technique meant top $27 \%$ will represent the high group and the low $27 \%$ will represent the low group. Finally, for each group, 11 students will represent the high muscle strength group and 11 students will represent the low muscle strength group.

The analysis used in this study is Analysis of Variance (ANOVA) with the significant level set at $\alpha<0.05$, and Tukey's post hoc test, where applicable. Normality and homogeneity tests were conducted before the data were analyzed.

\section{Results and Discussion}

There are two conditions that must be fulfilled before performing Analysis of Variance (ANOVA), namely, normality and homogeneity of the data. Normality test score on breaststroke swimming skills, were done on the overall data that use the bucket kick exercise, the overall data that use the tube kick exercise, the overall data of group with high leg muscle strength, the overall data group with low leg muscle strength, and data of each small group and large group which has particularly good high and low leg muscle strength. The overall normality test results showed that the value for treatment groups is significant $(p<0.05)$, and it can be concluded that the sample comes from a normally distributed population.

Homogeneity testing using Bartlett's test on all sample group showed that $\chi^{2}=0.639, \mathrm{p}<0.05$. Therefore all groups have the same variation or is homogeneous. Based on the analysis done, it can be concluded that the data in the score form of breaststroke swimming skills of students from each group is from a homogeneous population. Thus, the data for this research qualifies for hypothesis testing through parametric statistics.

Data analysis showed that there are differences in the mean value of breaststroke swimming skills acquired using the bucket kick exercise form and tube kick exercise form. The mean value of breaststroke swimming skills 
using the bucket kick exercise form is 16.408 , which is greater than the students who used the tube kick exercise form, which is 15.499 . Tukey test calculation results also proves that breaststroke swimming skills is better in the bucket kick exercise group as compared to tube kick exercise group $(\mathrm{F}=4.59, \mathrm{p}<0.05)$.

The average descriptive value for breaststroke swimming skills using the bucket kick exercise among students who have high leg muscle strength is 17.363 , which is more than students who use the tube kick exercise (14.272). Tukey test found that the group of students who have high leg muscle strength is better. This means that students who have high levels of leg muscle strength using the bucket kick exercise form is better than students who use the tube kick exercise form $(\mathrm{F}=10.30, \mathrm{p}<0.05)$.

The mean value of breaststroke swimming skills using the bucket kick exercise form for students with low leg muscle strength is 14.272 , which is less than the average descriptive value among the students who use the tube kick exercise form (16.727). Tukey test found that students who have low leg muscle strength using the tube kick exercise form is better than the students who use the bucket kick form $(\mathrm{F}=4.243, \mathrm{p}<0.05)$.

The results of descriptive analysis show that, in general, bucket kick exercise form is more effective for students who have high leg muscle strength $(\mathrm{F}=26.447, \mathrm{p}>0.05)$. This means that the null hypothesis is accepted that there is no interaction between the use of forms of exercise and leg muscle strength towards breaststroke swimming skills. It can be concluded that the use of the two forms of exercise i.e. bucket and tube kicks have its own effectiveness when adjusted according to muscle strength of the students. Form of interaction shown by the results of this calculation gives the obvious reason that there is diversity in the students' characteristics that would cause different interaction towards the forms of exercise.

\section{Implications}

\subsection{Selection of Weight Training Form}

Accuracy in choosing the form and methods of training should also be adapted to the physical condition of athletes as well as characteristics of muscle in order to gain a balance between physical ability and heavy burden. Choosing the right form of weight training is intended to prevent athletes from being hurt and can improve muscle demands with appropriate exercise program. If the opposite occurs i.e. the imbalance between physical conditions with the chosen form of exercise, then the result will be bad such as tissue damage or more serious damages to the muscles involved. Thus, the selection of appropriate exercises to be applied to an athlete must be tailored to their specific physical conditions.

\subsection{Application of Weight Training to Improve the Breaststroke Swimming Skill}

The research found that the bucket kick is better than the tube kick towards breaststroke swimming skills. This also means that the skill does not stand alone, but must be supported by other physical conditions such as leg muscle strength. However, changes and improvements in athletes differ from each other. Some are quick to adapt while others may take a longer time. Therefore, increases in training load must be in accordance to athlete's ability.

\subsection{The Use of Assessment by Observation in the Breaststroke Swimming Skills}

Training should be supported by assessment through observation of technique. If the technique is correct, swimmer will be able to do the breaststroke skill more effective and efficient. If technique is not perfected, the movement will be inefficient and more energy will be used.

\section{Conclusion}

Based on the evidence proven through this research, it can be concluded that:

1) In general, the bucket kick exercise is better if compared to tube kick exercise towards breaststroke swimming skills among students.

2) The breaststroke swimming skills of students with high leg muscle strength who were trained with the bucket kick exercise are better than students with high leg muscle strength who were trained with the tube kick exercise.

3) The breaststroke swimming skills of students with low leg muscle strength who were trained with the tube kick exercise are better than students with low leg muscle strength who were trained with the bucket kick exercise.

4) There is an interaction between forms of exercise and leg muscle strength towards breaststroke swimming skills. 


\section{References}

Bompa, T. O. (1994). Theory and Methodology of Training. Iowa:Kendal Publising Company.

Bompa, T. O. (1999). Periodization Training for Sports. Champaign Ilionos: Human Kinetics.

Bunn, J. W. (1972). Scientific Principles of Coaching. New Jersey: Englewood Clifft Prentice Hall, Publisher.

Colwin, M. C. (1980). Breakthrough Swimming. USA, Human Kinetics.

Counsilman, J. E. (1986). The Scientific of Swimming. Englewood Cliffs, New Jersy: Contenporary Books Inc.

Dal Monte, A. (1978). Klasifikasi Kegiatan Olahraga dalam Masalah-Masalah Kedokteran Olahraga. In L. Olahraga \& Coaching (Eds.), Edward Wiecrocek. Terjemahan Moh. Soebroto. Jakarta: Diklusepora, Depdikbud.

FINA Handbook. (2005). Contitutions and Rules, Swimming, Open Water Swimming, Diving, Water polo, Synhcronised Swimming and Doping Control. Fina oppice, 2005-2009.

Gagne, R. M., Briggs, L. J., \& Wager, W. W. (1992). Principles of Instructional Design. New York: Reinhart and Wiston, Inc.

Gusman, R. J. (1998). Swimming Drills for Every Stroke. USA: Human Kinetics.

Hamilton, N., \& Lute, K. (1997). Kinesiology: Scientific Basis of Human Motion. Dubuqe Guilford: Brown and Benchmark Publisher.

Hogg, J. A. (1982). Succes in Swimming. London: John Murray Publisher Ltd. Retrieved from http://www.SWIM.ee/models/-breast-Swim1.html

John, L. (1992). Science of Coaching Swimming. Champaign: Leisure Press.

Maglischo, E. W. (1993). Swimming Even Faster. USA: Mayfild Publishing Company.

Maglischo, E. W. (2004). Swimming Event Fastest. USA: Human Kinetics, Champign.

Pate, R. R., McClenaghan, B., \& Rotella, R. (1984). Dasar-dasar Ilmiah Kepelatihan. Terjemahan Kasyo Dwijowinoto USA: Saunders College Publishing.

Richards, R. (2004). Technical Course for Coaches. Jakarta: FINA/IOC Olympic Solidarity Development Program.

Sage, G. H. (1984). Motor Learning and Control: A Neuropsycological Approach. Dubuque, Iowa: Wm. C. Brown Publisher.

Sharkey, B. J. (1986). Coach's Guide to Sport Physiology. Illionis, Human Kineticks Publisher.

Singer, R. N. (1980). Teaching Physical Education. Boston: Houghton Miffin Company.

Singer. (1968). Motor Learning and Human Performance an Application to Physical Education Skill. New York: MacMillan Publishing Co, Inc.

Sweetenham, B. (2003). Championship Swimming. Human Kinetic, Champaign: USA.

Tony, L. (1989). Circuit Weight Training. England: Thorson Publisher Limited.

\section{Copyrights}

Copyright for this article is retained by the author(s), with first publication rights granted to the journal.

This is an open-access article distributed under the terms and conditions of the Creative Commons Attribution license (http://creativecommons.org/licenses/by/3.0/). 